\title{
TRASCENDENCIA DE LAS CREENCIAS RELIGIOSAS ENTRE ADULTOS MAYORES EN GRUPOS DE ALCOHÓLICOS ANÓNIMOS
}

\author{
Oscar Osorio Pérez \\ Universidad Autónoma Metropolitana, México
}

http://dx.doi.org/10.5209/rev_NOMA.2015.v45.n1.51332

\begin{abstract}
Resumen: En el presente artículo examino cómo las creencias religiosas para un sector de adultos mayores que participan en grupos de Alcohólicos Anónimos (AA) llegan a generar expectativas y motivaciones que disponen los rumbos de sus acciones en el continuo ordenamiento del mundo y su realidad. La investigación etnográfica nos muestra que las creencias religiosas no sólo son producto de la religión institucionalizada, sino que se desprenden también de la relación con instituciones seculares y de la propia dinámica en el orden de la vida cotidiana, donde se constituyen como mapas referenciales de resistencia frente a la adversidad y la incertidumbre.
\end{abstract}

Palabras clave: Adultos Mayores, Creencias religiosas, Alcohólicos Anónimos, Vida cotidiana.

The transcendence of religious beliefs which involves older adults in Anonymous Alcoholics supporting groups

Summary: This article examined how religious beliefs in a sector of the elderly who participates in a group of AA (alcoholics anonymous), could be able to generate expectations and motivations to provide a direction of their actions and their own system of their world and reality. Ethnographic research shows that Religious beliefs are not only the resulting product of an institutionalized religion, but are also arising from the secular relationship of institutions and from their own dynamic order of their common life activities where they build themselves as maps of reference and resistance against adversity and uncertainty.

Keywords: Older people, Religious beliefs. Anonymous alcoholics, common life.

\section{Introducción}

En México, la vida cotidiana de un sector importante de adultos mayores se enmarca en un contexto harto de precariedades y situaciones adversas, que aniquilan las posibilidades de vivir su envejecimiento razonablemente digno. La incertidumbre e inestabilidad del contexto social en que viven los ancianos, tienden a producir niveles elevados de angustia y aflicción, siendo así que el entorno social contribuye a la reproducción de una vejez marginal, donde uno de los elementos culturales de resistencia ante las precariedades e incertidumbres de la vida cotidiana, son las creencias religiosas. Aunque aún persiste la opinión de que las creencias religiosas son fuente de dominación, manipulación y reproducción de condiciones de pobreza, en la presente investigación muestro que las creencias religiosas ofrecen elementos de carácter simbólico con que se estructuran esquemas de percepción y acción, a partir de los cuales se construyen estrategias para enfrentar la adversidad. 
El trabajo de investigación etnográfica realizada entre adultos mayores Alcohólicos Anónimos (AA) en la ciudad de Xalapa México, fue mostrando que las creencias religiosas surgen de la reflexión y resistencia ante condiciones de vida adversas, constituyéndose como un recurso antropológico que va más allá de meras expectativas. Surgen donde la necesidad de transformar las condiciones reales de existencia no encuentran otra salida que la que ofrece la religión (Pereira, 1978). Siendo así que las expresiones de fe y esperanza que se manifiestan en las creencias religiosas, son el resultado de la asociación ininterrumpida de ideas originadas en la continua reproducción hipotética y empírica del mundo, donde lo sagrado y lo profano se entretejen y se constituyen en correspondencia.

Resabios analíticos de un positivismo esencialista, continúan viendo en la religión los vestigios de una ideología dominante: instrumento de manipulación y opresión. Pero poca atención se ha prestado a la crítica que desde la religión se hace del mundo. No sólo la religión institucionalizada, sino las creencias religiosas, impugnan lo que se advierte como contradicciones de la modernidad. Como producto del proceso de socialización, implican un cuestionamiento del modelo de la realidad, que pierde su carácter objetivo en el proceso de individualización de la creencia, generando al mismo tiempo cambios en la percepción de los modelos objetivos de la realidad, significando la autonomía subjetiva y racional de los hombres, transformando la realidad en hecho subjetivo.

La expresión de las creencias religiosas, en este caso entre adultos mayores AA, muestran que en "las sociedades secularizadas" la religión no desaparece, entre otras razones, porque los problemas de la vida social persisten y las fuentes de teorización y soporte filosóficas o científicas no explican ni compensan los misterios y ambigüedades de la vida, el sufrimiento y la incertidumbre, el problema del mal ni la inescrutabilidad del destino. Tampoco es la creencia religiosa la que desaparece cuando las instituciones religiosas pierden poder y prestigio, puesto que las negociaciones con lo divino son un salto imaginativo a partir de negociaciones bien terrenales (Delgado, 2001:235).

\section{1.- Creencias ordinarias}

El esfuerzo analítico por demarcar las creencias religiosas de las creencias ordinarias, nos conduce inevitablemente a cierto indeterminismo conceptual. En la práctica, los creyentes involucran sus creencias religiosas con todo tipo de creencias. Tanto las creencias religiosas como las ordinarias, nos indican grados de comprensión y entendimiento de aquello que sucede en el mundo, de los objetos, de los hechos y las personas, guardando grados de proporcionalidad con el saber certero, el conocimiento y la experiencia; pueden también hacerse explícitas en el sentido de opinión o expresión especulativa; y pueden también ser reconocidas como parte de un sentimiento, sobre todo cuando la creencia es generada a partir de una experiencia de verdadera relevancia o cuando a partir de la creencia, se busca vivir una experiencia única.

Siguiendo la línea argumentativa de Quesada (1998) toda creencia es un modo convencional de pensar los objetos, de tal forma que los objetos formarían el 
contenido de las creencias. Funcionan como estructuras de la mente que representan o configuran un mapa de la realidad (Armstrong, 1968). Partiendo de la lógica formal, una creencia tiene lugar cuando $p$ cree que $x$, entonces el sentido de la acción estaría determinada por la creencia en $x$. Pero en la práctica, si bien las creencias configuran disposiciones, no implican necesariamente una acción. Pasar de la disposición a la acción requiere que al trayecto de la experiencia se sumen otros elementos, como la conexión de las representaciones que producen la creencia, un fin, voluntad para la acción, motivaciones que la sustenten y consideraciones como razones justificadas.

No sobra preguntarse aquí porqué las creencias, entendidas como disposición a una conducta, no siempre producen las conductas expresadas en la misma creencia. Creer no implica necesariamente actuar como se cree. Contrario a una lógica teórica conductista, hemos aprendido que en una acción determinada pueden intervenir distintos estados mentales y anímicos que las alienten o las inhiban, y que las conductas expresadas no parten de un mismo estado mental, anímico u orden de ideas: las mismas creencias pueden expresarse en diferentes conductas y las mismas conductas pueden tener su origen en distintas creencias (Ryle, 2005, Damasio, 2010, Linden, 2010).

Hay una tendencia a pensar las creencias como producto de una mente individual, lo cual tiene sentido. Creer, escribe Hervieu-Léger (2005:122-123) presenta dos niveles de estructuración: las creencias inculcadas por los aprendizajes primarios, de los que puede tenerse la sensación de haber nacido con ellos; y las creencias formalizadas, de las que se puede dar cuenta y extraer de forma consciente implicaciones prácticas para la vida. En este sentido, cada persona tiene una creencia particular respecto a determinado objeto, y al mismo tiempo, la creencia tiene elementos de concordancia que le son comunes a otros hombres. Esto se debe a que las creencias no sólo son compartidas, sino que son aprendidas y constituidas en los marcos de comunicación de la dinámica de relaciones sociales. Luis Villoro (1992:71) nos ha enseñado que las creencias pueden pensarse mejor si se refiere a ellas como disposiciones adquiridas, que causan un conjunto coherente de respuestas determinadas por un objeto o situación objetiva.

\section{2- Creencias religiosas}

Buena parte de los estudios que vinculan las creencias religiosas con diversos ámbitos de la vida social, ha ponderado el análisis del aspecto religioso más que el aspecto disposicional de las creencias (Ramírez y De la Torre, 2009; Burbano 2010; Soto-Sonera 2009; González, 2004; Polanco y Orellana. 2010). El trabajo de investigación entre adultos mayores $A A$, fue revelando que si bien las creencias religiosas se asocian con elementos de la religiosidad institucional, no se limitan a expresiones derivadas de un proceso de adoctrinamiento ideológico-religioso, festividades o rituales. La plausibilidad de las creencias y la experiencia religiosa trascienden las formas institucionales de la fe, por lo que las creencias religiosas no son sistemas de creencias entendidas como cuerpos de doctrinas canónicas que se limitan a la producción teologías y prácticas institucionalizadas. 
Para entender la trascendencia de las creencias religiosas entre adultos mayores $A A$, en el proceso de investigación fui considero la importancia no sólo de la dimensión religiosa, sino el estado disposicional de las propias creencias. Creer que $p$, sería estar en un estado tal que dispone a tener múltiples comportamientos en relación con $p$ según las distintas ocasiones que se presenten (Villoro, 1982:32). Creer implica tener una serie de expectativas formulables a modo de hipótesis, que regulan las relaciones ante el mundo. Al creer en un hecho, escribe Villoro (op.cit::32-33) considero que ese hecho forma parte del mundo real y por lo tanto, me relaciono con el mundo contando con su existencia. De lo anterior se desprende que la importancia que tienen las creencias religiosas como elementos de significación y valoración de las acciones está mediada por la experiencia. ${ }^{1}$

Cuidando de no caer en el ámbito de un empirismo extremo, considero también la importancia de los estados mentales, significados y motivaciones que configuran las creencias religiosas. Sin ser meras ocurrencias, las creencias religiosas son también producto de operaciones mentales que configuran intencionalidades ante la experiencia. Como todo estado mental, la creencia tiene un contenido u objeto al cual se dirige: lo creído por, a lo que Carlos Pereda le llamó Trama conceptual de la mente (1994:278). En tanto que lo religioso, remite a un sistema de símbolos que obra para establecer vigorosos estados anímicos y motivaciones en los hombres (Geertz, 1997:87). Tanto el sentido de creencia como el de religión, tienen en común disposiciones y motivaciones, por lo que al integrarlas, las creencias religiosas refieren a operaciones mentales adheridas a un cuerpo de símbolos portadores de elementos de significado en torno a los cuales se dispone la acción. ${ }^{2}$ Las creencias ordinarias y religiosas pueden exponerse como formas particulares de ideas, configurar ideologías y estar arraigadas como una convicción (Ortega y Gasset, 1968; Thompson, 1999); compartir la duda o la certeza en que algo suceda o no (Sádaba, 1978); pero se distinguen por que las segundas suponen algo más que una probabilidad, son un acto que compromete y al que se le otorga la máxima importancia(Berger, 1994:157).

\section{3.- Trascendencia de las creencias religiosas}

Entender la trascendencia que tienen las creencias religiosas en el orden de la vida cotidiana, implica no sólo poner atención a las prácticas institucionalizadas de la creencia, sino también a las expresiones que se desprenden de las experiencias y los relatos de los creyentes. Por eso, los marcos de referencia teóricos y conceptuales de la creencia religiosa requieren partir no del fundamento

\footnotetext{
${ }^{1}$ Como la sociedad, la religión y las creencias religiosas son un fenómeno dialéctico en cuanto que son un producto humano y sin embargo revierten continuamente sobre su propio causante (Berger 1999:15) ya que el mundo construido socialmente se internaliza en la conciencia individual no como un mundo por él construido, sino como algo distinto del producto humano (Berger y Luckmann, 1999, 83-97).

${ }^{2}$ Es importante notar que por lo menos en los dominios de una antropología de la religión, la veracidad o falsedad de las creencias religiosas no nos conciernen, sino las razones de su existencia, implicaciones, significados y efectos (Delgado, 2001:16-17).
} 
institucionalizado de las corporaciones religiosas, sino de la revaloración de los actores que las experimentan, a partir de aproximarse a fuentes de conocimiento social, que como explica Pujadas (2000:127) llevan aparejada la voluntad de profundizar en lo que las personas y los grupos hacen, piensan y dicen, con la finalidad de ensayar interpretaciones de la realidad a partir de la subjetividad individual y grupal.

Los relatos de historia de vida de los creyentes que fueron recabados entre adultos mayores que participan en $A A$, no refieren necesariamente a relatos históricos eminentemente verdaderos o reales objetivamente. Todo relato implica la narración del pasado en el presente, afectado por la pérdida de memoria, recuerdos selectivos, omisiones y sesgos intencionales o no. Los relatos y experiencias que se presentan para comprender la trascendencia de las creencias religiosas, tienen como objetivo mostrar la producción de significados e interpretaciones como proceso reflexivo de la experiencia personal y su realidad social. No espero que los relatos de vida se ajusten a experiencias que puedan ser verificadas con "escrupulosa cientificidad". Antes bien, los relatos de vida permiten un acercamiento a la vida cotidiana de los sujetos que expresan su subjetividad en el amplio proceso de significar: no son la expresión de meras narraciones descriptivas de la experiencia, sino elementos sistemáticos que significan y dan sentido a la experiencia. Esto es que los marcos de interpretación de la experiencia dan sentido a la propia experiencia, en función de que las estructuras de significado que preexisten a los sujetos y que constituyen referentes disposicionales son útiles para interpretar el mundo, no como si éste fuera transparente en su totalidad, sino como una totalidad de evidencias que cambian de una situación a otra (Schutz y Luckmann, 2003:29 y ss.). ${ }^{3}$

Durante el proceso de investigación encontré que algunos adultos mayores AA, expresaban cierto gusto por fingir haber vivido determinadas experiencias. Aun así, las narrativas de la experiencia no son meras confabulaciones, historias falsas cuyo propósito es el engaño deliberado. Se trata de reconocer los estados de subjetividad en la creencia religiosa y no de emitir juicios sobre la veracidad histórica u objetiva de las narrativas. Después de todo, escribe Williams James (1999:52) la mente humana puede creer con todas sus fuerzas en la presencia real de un conjunto de cosas de las que no se puede formar noción alguna; y el sentimiento de realidad puede unirse íntimamente al objeto de creencia que toda

\footnotetext{
${ }^{3}$ Por sentido bien pude entenderse una forma compleja de conciencia del hecho de que existe una relación entre varias experiencias, donde el sentido de las experiencias se construye a través de las funciones relacionales de la conciencia (Berger, 1997:32). En tanto que el proceso de significación, es la producción humana de signos que se distinguen por su intención explícita de servir como indicios de significados subjetivos (Berger y Luckmann, 1999:55). El significado es la manera en que el "yo" considera su vivencia, reside en la actitud del "yo" hacia esa partede su corriente de la conciencia que ya ha fluido hacia su "duración transcurrida" (Schutz, 1972: 99 y ss.). Es decir que el sentido no es una cualidad inherente a ciertas experiencias que surgen dentro de nuestro flujo de conciencia, sino el resultado de la interpretación de una experiencia pasada contemplada desde el presente con una actitud reflexiva, puesto que constituyen universos de significado que orientan y en los que se conducen los propios sujetos.
} 
la vida se polariza de raíz, a través del sentido de la existencia de la cosa en la que se cree.

\section{2.- La trascendencia de las creencias religiosas en Alcohólicos Anónimos}

Para Alfred Schutz y Thomas Luckmann (2003:198 y ss.) el mundo de la vida cotidiana se presenta como realidad eminente, dominado por motivos pragmáticos y planes de vida en un mundo ordenado. La "actitud natural" es el estado de conciencia en el cual se acepta la "realidad de la vida cotidiana" como dada. Pero el mundo de la vida se compone de algo más que la realidad cotidiana. La estructura temporal del mundo de la vida está vinculada al problema de la sedimentación y de la activación de la experiencia pasada (Ibidem.:29). Regularmente nos hundimos en el sueño y renunciamos a la actitud natural a fin de perdernos en otros mundos ficticios y fantasías (Ibidem.:41 y ss.).

En ocasiones, el mundo entra en un estado de crisis y en la mente de los hombres surgen dudas respecto del destino del mundo. Es posible también que a determinados individuos "el mundo de la vida" les parezca más o menos estable, pero aun así, puedan estallar crisis de sentido. Por ejemplo, cuando los hombres no son capaces de alcanzar las metas que de ellos se esperan o las metas que ellos mismos han planificado, surgen crisis de sentido donde los hombres ven su vida amenazada y donde los estados anímicos de los hombres pueden tornarse oscuros. En el contexto de una modernidad plural, se espera encontrar los medios y mecanismos adecuados que apoyen la superación de las crisis, pero es precisamente el pluralismo moderno que conduce a la relativización total de los sistemas de valores y esquemas de interpretación, lo que produce la "pérdida de lo que se da por supuesto" y la consecuente pérdida de confianza y crisis de sentido (Berger y Luckmann, 1997:75-80).

Todas las instituciones conllevan un sentido de acto y las más relevantes son aquellas cuyas principales funciones consisten en controlar la producción y transmisión de sentido (Berger y Luckmann, 1997:40). Las instituciones religiosas por ejemplo, son comunidades que transmiten categorías de sentido con pretensiones de generalidad, sin embargo, esta pretensión es impugnada por el sentido objetivo de los esquemas de acción de las demás instituciones (ibídem. 55). El desencanto con las instituciones religiosas ha generado cierta distancia con su feligresía, aunque la fe persiste. En este sentido, la fe se ha insertado en un proceso de desinstitucionalización, adquiriendo un amplio margen de independencia y disociación con las instituciones religiosas, quedando cada vez más restringidas al ámbito de la conciencia (Luckmann, 1973; Mardones, 1996). Paralelo a las instituciones religiosas, "instituciones secundarias" como lo son las instituciones asistenciales, cumplen con la función de evitar que se agraven dichas crisis de sentido, sin que ello implique la desaparición de la fe y la creencia religiosa. Es el caso de los grupos de AA que funcionan como instancias reproductoras de sentido, a partir de lo que Berger y Luckmann (1997:81) han llamado "programas" para el manejo de la interacción social y para la "ejecución" 
de un currículo vitae determinado, que proporciona modelos probados a los que la gente puede recurrir para orientar su conducta.

Los grupos de AA tienen su propio programa de recuperación basado en doce pasos, doce tradiciones y doce conceptos, que se constituyen como un plan de vida y se exponen como sugerencias basadas en la experiencia que los primeros AA consideraron importantes para lograr la sobriedad. La aplicación del programa de $A A$, que orientan la acción a pensar y vivir diferente, declara el cumplimiento de doce promesas, que entre otras, augura la revelación de un nuevo sí mismo, una nueva forma de libertad, de confianza y felicidad.

AA es una instancia reproductora de sentido en la medida que ofrece orientación respecto del deseo no sólo por dejar la bebida, sino de comprender el alcoholismo como una enfermedad, aprender a vivir con ella en sobriedad y aprender a vivir con quienes la padecen, bajo la premisa de depositar la fe en un poder superior. No obstante de ser la principal función de AA lograr la sobriedad de sus miembros, los grupos de AA alientan la movilidad social, el acenso económico y mejorar las relaciones familiares a través de un cambio de actitudes y valores (Módena, 2009:36ss). En este sentido, AA funciona a partir de un "programa" y "ejecución de currículo vitae", como modelos para la orientación y acción de la conducta ante la exclusión y la marginación social de los alcohólicos, que limita el acceso a mejores condiciones de vida, salud y bienestar mental.

\section{1 - La trascendencia de lo sobrenatural}

No obstante que los mismos creyentes asocien sus creencias religiosas con la intervención de lo sobrenatural, lo sagrado o divino, no debieran reducirse a estos elementos de carácter convencional. Durkheim mostró que la religión y las creencias religiosas eran un asunto eminentemente social y Max Weber evidenció que las religiones estaban orientadas al mundo. El actuar o el pensar religioso o mágico, escribe, no puede abstraerse del círculo de las acciones con vistas a un fin de la vida cotidiana (Weber, 1996:328). ${ }^{4}$ Lo sobrenatural puede identificarse con el reino de lo misterioso, pero también puede manifestarse no como una creencia extraordinaria, ni siquiera como una creencia, sino parte de una relación incuestionable (Delgado, 2001:21). Por otra parte, no todas las personas que se consideran religiosas o manifiestan creencias religiosas, han tenido experiencias

\footnotetext{
${ }^{4}$ La relación entre creencias religiosas, mitos y seres espirituales puede rastrearse en los postulados de Tylor, Durkheim, Otto y Eliade. Para Edward B. Tylor, el hecho religioso tiene su base en el animismo, la creencia de que los seres humanos comparten el mundo con seres extracorpóreos, santos, demonios, hadas, dioses, ángeles, etc., que se manifiestan en experiencias regulares como sueños, trances, visiones, sombras o reflejos (Harris, 1997:361-362). Durkheim (2000:35-41) descubrió que las creencias religiosas se caracterizan por suponer una clasificación de las cosas que se presentan en géneros opuestos: los sagrado y lo profano, siendo así que los mitos, los gnomos, las leyendas, son sistemas de representaciones que expresan la naturaleza de las cosas sagradas. Rudolf Otto (2007) comprendió que la experiencia religiosa era el fundamento de todas las religiones, dándole a esta experiencia el nombre genérico de lo numinoso.MirceaEliade (1999) concentró sus esfuerzos en revelar las manifestaciones de lo sagrado que contenían todo rito, mito, creencia o figura divina.
} 
consideradas extraordinarias en términos de los numinoso, lo santo, lo divino o lo celestial, ni les hace mucho sentido referirse entidades espirituales y seres sobrenaturales. Si bien las creencias religiosas están íntimamente relacionadas con lo sagrado, la trascendencia de las creencias religiosas nos dice Peter Berger (1999:47) refiere a un tipo de poder misterioso e imponente que sale de la rutina normal, y aun cuando es aprendido como algo distinto del hombre, está sin embargo referido a él y en ciertos objetos de experiencia.

Durante el proceso de investigación en $A A$, fui entendiendo que la trascendencia de las creencias religiosas debe buscarse no sólo en el acto ritualístico que conecta con lo sagrado, sino en el orden de las preocupaciones prácticas de la vida cotidiana. Después de todo, la mayoría de los hombres no tienen experiencias religiosas extraordinarias en el sentido de encuentro con seres espirituales y lo que con normalidad se manifiesta de estas creencias no es tanto el carácter excepcional o extraordinario de lo divino, lo sagrado, santo, celestial, glorioso, o sobre humano, sino el acto de fe en que aquello suceda.

Entre los Alcohólicos Anónimos, las señas inequívocas de la existencia de un poder superior no siempre se asocia con el orden de lo sobrenatural, sino con experiencias bien terrenales tales como el mantenimiento de la unidad del grupo en que participan, la apertura de un nuevo grupo de AA, la llegada de un nuevo miembro o la reincorporación de otro, el sentimiento de empatía al interior del grupo o en la gracia de que en ese día no se ha vuelto a beber. La creencia en la manifestación de Dios, si bien es una experiencia deseada por un buen número de alcohólicos, no necesariamente se busca como una experiencia mística que trascienda la experiencia y se manifieste en forma de milagro o encuentro verdadero con la presencia de Dios, tal como narra Bill W., co-fundador de AA, su propia experiencia. ${ }^{5}$

Al igual que Bill W., algunos alcohólicos han experimentado este encuentro con Dios o experiencia mística, antes o después de haber llegado por primera vez a AA, aunque de forma muy distinta. Rubén cuenta cómo despertó en el puerto de

\footnotetext{
${ }^{5}$ Bill, sumido en una depresión y deseando verdaderamente dejar de beber, pensó que podía ser capaz de hacer cualquier cosa, aunque no podía creer en el Dios que le ayudaría a lograrlo. En un estado de redención absoluta, pero sin fe ni esperanza, pidió que se manifestara ese Dios, si es que existía. De pronto: "mi cuarto resplandeció... se apoderó de mí un éxtasis.... Luego, visto con los ojos de la mente, estaba ahí una montaña y yo estaba de pie en su cumbre, en donde soplaba un gran viento, que no era de aire, sino de espíritu; con una fuerza grande y pura, soplaba a través de mí. Entonces llegó el pensamiento resplandeciente: Eres un hombre libre...Al estar más calmado, me embargó una gran paz... Llegué a estar gradualmente consciente de una presencia que parecía un verdadero mar de espíritu vivo... Esto, pensé, debe ser la gran realidad, el Dios de los predicadores... Parecía que estaba poseído por el absoluto y se profundizó la curiosa convicción de que, sin importar qué tan equivocadas parecieran estar las cosas, no había ninguna duda de la realidad fundamental del universo de Dios. Por primera vez, sentí que realmente pertenecía; supe que era amado y a mi vez podía amar. Agradecí a mi Dios, que me había dado un vislumbre de su Yo absoluto. Incluso, aunque era un peregrino en un camino incierto, no necesitaba preocuparme más, porque había vislumbrado el gran más allá en un camino incierto, no necesitaba preocuparme más, porque había vislumbrado el gran más allá (A.A, 2014:114-115).
} 
Veracruz a las diez de la mañana al volante de su camioneta. Tres amigos le acompañaban y al igual que él, amanecieron totalmente ebrios. No podía recordar cómo fue que recorrieron por autopista los casi cien kilómetros de distancia entre la ciudad de Xalapa y el puerto. Al regresar a su casa, en sueños se revelaron imágenes de un accidente que tuvo lugar en su fuga de madrugada a Veracruz, en el que sus amigos y él habían perdido la vida. ¿Cómo había sido posible? Las imágenes se volvían a revelar en su mente después de varios días, como una experiencia real. Preguntó a sus amigos qué había pasado en ese viaje y nadie pudo dar detalle del mismo. La experiencia de una muerte casi cierta había derivado en una muerte moral y espiritual, que sólo superó al entender su experiencia como un milagroso encuentro con un poder superior.

Entre quienes asisten a grupos de AA, la creencia de que "Dios se ha manifestado" se hace evidente en experiencias relacionadas con la salvación, la recuperación y la dicha, que puede o no incluir la idea de haberse realizado un milagro. Aunque también la creencia en la manifestación de dios se expresa en experiencias del orden de lo cotidiano, que suelen no ser verdaderamente profundas, aunque si importantes. Miguel narra cómo después de once años de abstinencia de alcohol, volvió a beber y llegó a un grupo de AA veinticuatro horas donde tuvo que pasar tres meses. Al tercer día de estancia encontró arrumbada una botella de tequila que bebió compulsivamente. Al ser descubierto, ya en estado de ebriedad, le exigieron que revelara quién le había pasado de contrabando el alcohol, a lo que respondió: "Dios"... "Dios se manifestó".

Las narraciones de algunos alcohólicos respecto a la manifestación de Dios en sus vidas, involucra no solamente la "salvación milagrosa personal", sino el reconocimiento del "milagro de la salvación en los otros". Joel comenta cómo después de lograr algunos unos años de sobriedad, aplicado al programa de recuperación de $A A$, sintió lo que llama un vació espiritual y la necesidad de ir en búsqueda de Dios y comprobar que verdaderamente existe. Acudió entonces a visitar al Padre Daniel Nolasco -psicólogo y fundador del primer grupo de Homosexuales Anónimos y grupos AA. "Me postré frente al altar y comencé a pedirle a Dios que se manifestara". El padre Daniel, que conocía muy bien a Joel, lo interrumpió de súbito y le pregunto qué hacía. "Vengo a pedirle a Dios que se manifieste en mí". "Aquí no vas a encontrar a Dios, le dijo Daniel, Dios está allá afuera y tú lo sabes". Después de una corta plática, Joel salió de la parroquia. Recordó a ver visto antes de entrar a la iglesia a "un tipo tirado en la calle, con medio cuerpo en la banqueta y medio cuerpo sobe el pavimento. Salí de la parroquia y ahí seguía, supe que en ese momento también se me había manifestado Dios". Joel entendió la manifestación que andaba buscando en su interior y en la iglesia. Llevó al indigente a su grupo de AA.

Igual que sucede en múltiples relatos de vida de los alcohólicos, Joel encontró en la experiencia de "otro" la revelación de la razón de ser de su propia existencia. "Yo soy la muestra evidente de que Dios existe", suelen expresar alcohólicos en recuperación. Pero al pasar el tiempo, algunos alcohólicos como Joel han perdido cierta confianza y sentido en sus vidas, aun cuando la participación en grupos de AA no se limita únicamente a la asistencia a sus juntas de recuperación, sino que 
refiere al apego de un programa de recuperación que exige la unidad y el servicio: realizar actividades al interior del grupo y con la comunidad amplia de AA. "Ni los mejores AA tienen una estabilidad absoluta. Con frecuencia encontramos desafíos mayores en problemas de la vida que son constantes" dice Joel. Por eso, si bien la recuperación del alcohólico se considera un asunto de orden personal, es fundamental también que los alcohólicos vivan la experiencia de ayudar a otros y se ayuden mutuamente, pues de eso depende la recuperación personal.

\section{2- Las trascendencia del dogma}

Con frecuencia se considera a las creencias religiosas como la expresión de una fe ciega basada en dogmas, no verificadas y fácilmente refutadas. Al definir la religión como creencias y rituales que conciernen a seres o fuerzas sobrenaturales de un reino extraordinario, no empírico, misterioso e inexplicable, se supone también que las creencias religiosas requieren entonces de una postura dogmática de validación ante signos que están más allá de la lógica y lo racionalmente demostrable. Bertrand Russell (1979) por ejemplo, expresó con aplomo que no era cristiano puesto que no había encontrado evidencia alguna respecto de la verificación de los dogmas cristianos, ni elementos lógicos viables de los argumentos a favor de la existencia de dios. No encontrando ninguna razón práctica para que la gente crea en algo que no es verdad, la religión le parece deshonesta y dañina.

El pensamiento filosófico de Russell respecto del hecho religioso, parte de un modelo de razón ilustrada que asume criterios precisos, certeros, fijos y generales para argumentar, y programas fundamentalistas de justificación (Bernstein en Díaz, 1994). Este racionalismo austero supone que si algo es verdad debe creerse y si no lo es no debe. Cabe preguntarse si este tipo razonamiento es útil para entender la complejidad de las creencias religiosas. Suponer que la lógica y el razonamiento son propiedad de la mente y el cerebro, es ignorar que pensar lógicamente es pensar de una manera impersonal y que el pensamiento impersonal es derivado del pensamiento colectivo; quien piense lógicamente reglará sus ideas y sus acciones en conformidad con las representaciones colectivas de su sociedad y al hacerlo vivirá en el reino de la verdad (Díaz, 1998:89). Las creencias religiosas no debieran desvalorarse por su acientificidad o indemostrabilidad, puesto que son creencias, es decir, disposiciones para la acción y no elaboraciones teóricas con fundamento epistémico y cuerpo definido de conceptos sistematizados. En tanto que considerar "dogma" como "lo incuestionable", impide ver elementos de relatividad dogmática que flexibiliza las posturas del creyente: los dogmas religiosos pudieran determinar la opinión, pero no controlan por completo la expresión de las opiniones.

Los adultos mayores que asisten a grupos de AA, aprenden que dejar de beber sólo es posible bajo por lo menos dos requisitos: aceptar su condición de alcohólicos y entregarse por completo a la creencia de que sólo con la ayuda de un poder superior pueden mantenerse en estado de sobriedad y buen juicio. Cuando participantes de AA están por comenzar a compartir su experiencia de 
vida, agradecen a Dios o poder superior por haberse mantenido sobrios por lo menos durante las últimas veinticuatro horas. Por supuesto, no todos los asistentes a AA aceptan la creencia en un poder superior y pueden empezar a compartir su experiencia diciendo "gracias a mi poder superior que no he bebido ni he generado hacerlo", como una simple rutina sin mayores expectativas (O' Reilly, citado en Brandes, 2004:116).

Hervieu-Léger (2000:121-123) nos ayuda a entender que las creencias, como convicciones individuales y colectivas, si bien no se desprenden de la verificación y la experimentación, de los modos de conocimiento y el control que caracteriza al saber, encuentra su razón de ser en el hecho de que dan sentido y coherencia a la experiencia subjetiva de quienes las mantienen. La creencia puede escapar a la demostración y verificación experimental, pero las creencias religiosas se manifiestan como válidas no porque sean verdaderas o falsas, sino porque tienen valor y vigencia en el continuo e inacabado proceso de regulación de la vida, de acuerdo a lo que se dice creer.

Dentro de los grupos de AA, algunos adultos mayores han vivido lo que se denomina "la experiencia". Se trata de un ejercicio de escritura y confesión de las experiencias dolorosas y traumáticas de las historias toda la vida: "buscar en el historial las razones por las que se bebe tan obsesivamente". No hay una única forma de realizar esta experiencia, aunque la mayoría de quienes la han realizado dicen haber encontrado un estado de paz y tranquilidad interior única. Para algunos Dios se ha manifestado en el "alma" o en el "corazón", otros le han visto y han conversado con él y unos más afirman que Dios les ha mirado y les ha dicho que "todo está bien". Independientemente de cómo haya sido su experiencia, la manifestación de un estado de paz y tranquilidad, el sentimiento de alivio y consuelo es un hecho generalizado que nadie pretende demostrar: "sólo puedo hablar de Dios a partir de mí experiencia".

Las experiencias de los AA muestran que las creencias religiosas tienen grados de alteración que van más allá de su polarización entre la certeza y la incerteza, no son disposiciones totalizadoras ni fijas. La combinación de un contexto particular y experiencias verdaderamente importantes en la vida de las personas detonan la creencia religiosa, y las creencias religiosas se vuelven a los individuos orientando a su vez prácticas religiosas, que son también prácticas sociales que no pueden ser situadas al margen de las negociaciones intersubjetivas con lo sobrenatural, lo incognoscible o lo trascendente, aunque no signifiquen siempre lo mismo y puedan, como referentes, no existir en esos términos (Delgado, 2001:235).

\section{3 - Las creencias religiosas trascienden la "naturaleza humana"}

Las creencias religiosas se han pensado también como inherentes a la naturaleza humana: "el hombre necesita conocer", "el hombre tiene la necesidad de creer en alguien superior a él". Adherir la propiedad de "necesidad" a las creencias religiosas, naturaliza a las creencias mismas, tal como si no fueran el resultado de la actividad humana. 
La antropología decimonónica representada por Frazer y Tylor, orientaron el estudio de la religión como parte de un proceso evolutivo-psicológico de corte universal, que ha pasado del pensamiento mágico a las creencias religiosas (Frazer, 1981). Las creencias religiosas según Tylor (1977:122ss., 345ss.) se suceden en el hombre primitivo al enfrentarse a fenómenos que escapan a su control, como los sueños y la muerte, "viéndose en la necesidad" de crear explicaciones para comprender dichos fenómenos. Por otra parte, Bronislaw Malinowski, propuso que para entender las creencias fundamentales de un pueblo, habría que centrar nuestro interés en sus prácticas mágicas (1973:383). Las prácticas mágicas tendrían la finalidad instrumental de controlar el orden del mundo, y una finalidad individual: satisfacer necesidades psíquicas (Malinowski, 1985:121). El interés pragmático que el hombre siente por ciertos aspectos del mundo interno y la necesidad de suplir mediante la magia el control racional y empírico de ciertos fenómenos, generarían tensión de las necesidades instintivas (op. cit:54); y las fuertes experiencias de la emoción, conducirían de una u otra suerte, al culto y al credo (op. cit:5). Para Malinowski, la magia es similar a la ciencia en que siempre cuenta con una meta definida que está íntimamente relacionada con instintos, necesidades o afanes humanos (op. cit.:32).

Una lectura ligera de las tesis anteriores, ha contribuido a pensar las creencias religiosas como parte de una necesidad inscrita en la naturaleza humana, en un tipo de "necesidad innata por conocer y explicarse el mundo", sin considerar que la misma antropología de principios del siglo XX, bien comprendió que la naturaleza humana no existía sino en el orden de la cultura, siendo que la "naturaleza humana" como sistema de condiciones que se manifiestan en el organismo humano, solo se hace inteligible en el marco cultural y en su relación con el ambiente físico (Malinowski,1982:97). Por lo que la naturaleza de la magia y de las creencias religiosas, no se reduce a una necesidad de orden psíquico-biológico, sino que se desprenden de elementos en las dimensiones psíquicas, biológicas y culturales.

La enfermedad y la vejez, por ejemplo, pueden ser entendidas como estados naturales de la vida y los ancianos bien pueden aprender a vivir las consecuencias de su vejez, sin embargo, no dejan de causar estados de angustia o miedo. En el diario vivir de los ancianos, tristezas y alegrías pueden presentarse como expresión de las emociones de forma ordinaria. La tristeza o alegría sobre cualquier hecho real depende de los esquemas y esperanzas más remotos con los que esté relacionado; su significado y su forma le suministran la parte más importante de su valor (James, 1999:114). Pero cuando los ancianos se enfrentan con la experiencia de la muerte, una serie de premoniciones consternan su mente y los hace emocionalmente más vulnerables, ¿surge entonces la creencia religiosa a causa de la fragilidad de la naturaleza humana?

Algunas posiciones académicas se parecen mucho a las intuiciones generales respecto del por qué tenemos creencias religiosas: necesitamos respuestas que nos den seguridad y nos hagan sentir mejor, nos brinden consuelo y seguridad. Ciertas líneas filosóficas mantienen que la creencia religiosa es una necesidad ineludible que el hombre tiene que satisfacer, cuyo principio se sustenta en la 
necesidad de conocer y no ser capaz de hacerlo plenamente ni con seguridad total (De la Pineda, 1998:28-29). Aunque hay personas para quienes el mal constituye algo radical y general, que requiere un remedio sobrenatural (James, 1999:110)fundamentar las creencias religiosas como inherentes a la naturaleza humana sólo tiene sentido si se vinculan con las capacidades cerebrales y mentales que tienen los humanos para construir relatos sensoriales que pueden extenderse a niveles de significado, percepción y cognición, aunque no puedan ser demostradas (Linden, 2010:236-248). Estos relatos pueden implicar una serie de ajustes en la experiencia ordinaria con lo que la enfermedad y muerte pueden superarse.

\section{4.- Las creencias religiosas trascienden la racionalización}

La creencia religiosa escribe De la Pineda (1998:36ss.) tiene el mismo fundamento que cualquier otro tipo de creencia: el asintonismo. ${ }^{6}$ La realidad conocida, dice el filósofo, a veces se manifiesta y a veces se oculta, tiende a manifestarse pero no lo hace del todo: el sujeto que pretende conocer nunca lo hace plenamente y con seguridad tampoco alcanza su meta, a esto le denomina asintonismo gnoseológico. La diferencia entre las creencias religiosas y otro tipo de creencias, siguiendo al mismo autor, es que las primeras tienden a pensarse como si tuvieran un valor absoluto y el valor absoluto exige una adhesión absoluta, lo que lleva a la siguiente afirmación: las creencias religiosas son las más radicales de todas las creencias por su carácter incondicional, su apertura y religación al ser absoluto. Esta visión desorbitada de lo que son las creencias religiosas, nos lleva a pensar en ellas como actos irreflexibles y concluyentes.

En ocasiones, los AA pueden intentar ofrecer pruebas que sustentan la validez de sus creencias, remitiéndose a un recuento biográfico de experiencias personales, donde sucedieron milagros, revelaciones o experiencias místicas. Pero los argumentos que sustentan la creencia, es decir, las "pruebas que validan la creencia", son intentos para fijar y regular el uso de las expresiones religiosas, mediante lo cual están expresando actitudes particulares ante la vida y no formulando teorías (Mejía, 2006:19). La racionalización de la creencia religiosa distorsiona la creencia misma, puesto que no se muestra mediante razonamientos o apelando a fundamentaciones corrientes, sino más bien regulando toda su vida (Wittgenstein, 2002:130 y ss.).

Las creencias religiosas expresadas por los AA, tampoco se afirman en función de alcanzar un status de verdad. Entender el "programa de recuperación de AA", dice Luis, requiere dejar a un lado los cuestionamientos de la razón, puesto que el programa va en contra de la forma en que se ha venido pensando, de los deseos personales y de la propia lógica. Lo mismo que la certidumbre, la conceptualización axiomática de la creencia religiosa pervierte la fe y rechaza la fe (Berger, 2006:173) puesto que en el campo de la fe hay una preeminencia de la vida de fe sobre la teorización de la misma. La verdad experiencial, cercana a la

\footnotetext{
${ }^{6}$ Asintonismo indica la dirección o movimiento hacia una meta que nunca se alcanza.
} 
contemplación fruitiva, penetra más en la realidad de lo último que el pensamiento discursivo (Mardones, 1998:111).

La racionalización y sistematización progresiva de las creencias religiosas hizo de ellas cuerpos unificado de conceptos y doctrinas, estableciendo un orden eclesiástico burocratizado e institucionalizado. En los campos de la escolástica y teologías cristianas, la teorización no sólo tiene sentido, sino que vindica su derecho de existencia. Pero en los amplios dominios de la cultura, las razones del creyente tienen su soporte en la confianza y fe, y no en la racionalización teológica e institucionalizada de la creencia religiosa, dirigida a las opiniones y acciones del creyente.

No obstante que las creencias religiosas no se fundan en la certeza intelectual y racionalista, tampoco lo hacen en el marco de la inocente credulidad, sino en la posibilidad y el esfuerzo propio de la fe, en el amor y la confianza (Barret, 1994:242). En este sentido, las creencias religiosas se van construyendo en un contexto de mediación de significados, en y al margen de las instituciones religiosas, de su racionalidad y de la lógica cultural. Se construyen también como fuente de conocimiento compartido, en función de eventos particulares de la vida cotidiana que son de verdadera relevancia para los creyentes. Las creencias religiosa hacen explícita la confianza en que lo que está más allá de este mundo significa algo para mí... la confianza de que dios no abandona su creación (Berger, 1994:169).

\section{Conclusiones}

En la modernidad, el pensamiento religioso no sólo parece poco importante, sino obstaculizante y pernicioso. Los usos de la racionalidad objetiva pueden ser útiles ante determinadas experiencias, pero carecen de utilidad y razón en otras. La modernidad supone la ocultación de dios, de lo religioso y de la fe, pero esa ocultación no es ausencia sino presencia latente y potencial. Peter Berger sugiere que la religión tendría como función evitar el caos y el dominio de la contingencia. En la modernidad, las creencias religiosas son fácilmente sustituidas por otras ideologías, filosofías y ciencias, pero siempre regresan a los hombres, no siempre como explicación del mundo pero siempre como consuelo. No sólo se trata de controlar las contingencias más inquietantes, sino hacerlas soportables cuando no pueden evitarse. Así, experiencias relacionadas con la muerte, la pérdida, la soledad, enfermedad, requieren de un soporte que la ciencia, la filosofía y otras ideologías no son capaces de ofrecer o ser aceptadas, es aquí donde tienen lugar la trascendencia de las creencias religiosas.

Como parte del mundo socialmente construido y socialmente mantenido, las creencias religiosas requieren para su reproducción una base social que Peter Berger llamó "estructura de plausibilidad", que es la base social que hace posible la continuación de la existencia del mundo tal como es para los seres humanos (1999:74). En la esfera de lo religioso, las creencias requieren de un soporte social como peculiar contexto en el que la comunidad del creyente le confirme su creencia y la haga plausible (Berger, 1994:158-159); y de la invocación a la 
autoridad de una tradición como la expresión visible de una filiación que el creyente revindica. En este sentido, lo esencial no es el propio contenido de la creencia, sino su integración a la forma de creer y expresar la creencia, que se justifica completamente a través de la inscripción que revindica un linaje creyente (Hervieu-Léger, 2000:128-237). Finalmente, la trascendencia de las creencias religiosas radica no en su relación con el orden de lo sobrenatural, sino en aquello que va más allá con lo que los seres humanos están familiarizados (Berger, 1994:24) y no es la idea de lo santo lo que hay que comprender, sino su experiencia, que es trascendente porque se manifiesta distinta a toda experiencia ordinaria en fenómenos relativamente poco convencionales (Ibidem: 166-167).

Diversos estudios sobre la vejez en México, enfatizan en la relación vejez-calidad de vida como una manera de dar cuenta de las condiciones de vida de los adultos mayores y la necesidad de prever que estas condiciones se hagan efectivas (Montes de Oca, 2010; Robles, 2006; Vázquez, 2001). La calidad de vida se ha entendido como un estado de bienestar en el que elementos de carácter objetivo tales como empleo, salud, seguridad social, alimentación y vestido, se entrelazan con elementos subjetivos como son la felicidad, satisfacción y sentimientos de bienestar. En la búsqueda por mejorar su calidad de vida, los adultos mayores consideran su condición de bienestar en relación al acceso de bienes materiales y simbólicos que le permitan su reproducción. Pero la vida material y la vida mental se conjugan en la dimensión afectiva de la vida cotidiana, donde el sentido de la "experiencia" se configura como elemento supremo sobre la razón. Por eso las creencias religiosas no son recursos o herramientas de sobrevivencia, tampoco buscan sólo "satisfacer necesidades", sino elementos de producción de sentido y significado en el continuo proceso de la experiencia humana, donde la fe, escribe Mardones (1998:111) se mide más por la ortopraxis que por la ortodoxia, por la recta práctica y vivencia de la fe que por su adecuada expresión. [...] en último término, la fe se acepta por experiencia propia. En este proceso, las creencias religiosas juegan un papel importante en un sector amplio de estos adultos mayores, al orientar sus acciones en la búsqueda de mejores condiciones de vida, con base en las creencias que gestionen su experiencia en la vida cotidiana.

\section{BIBLIOGRAFÍA}

(2014) A.A, La historia de Bill Wilson y cómo llego al mundo el mensaje de Alcohólicos Anónimos, Ed. Central Mexicana de Servicios Generales de Alcohólicos Anónimos, A.C,México.

(1968) ARMSTRONG, David, A Materialist Theory of the Mind, Ed. Routledge and Kegan Paul, London.

(1994) BARRET, Cyril, Ética y creencia religiosa en Wittgenstein, Ed. Alianza Universidad, Madrid.

(2006) BERGER, Peter, Cuestiones sobre la fe. Una afirmación escéptica del cristianismo, Ed.Herder, Barcelona.

(1999) BERGER, Peter, El dosel sagrado. Para una teoría sociológica de la religión, Kairós, Baeceona 
(1994) BERGER, Peter, Una Gloria lejana. La búsqueda de la fe en época de credulidad, Ed. Herder, Barcelona.

(1999) BERGER, Peter y Thomas Luckmann, La construcción social de la realidad, Ed. Amorrortu, Bueno Aires.

(1997) BERGER, Peter y Thomas Luckmann, Modernidad, pluralismo y crisis de sentido. La orientación del hombre moderno, Ed. Paidós, Barcelona.

(2004) BRANDES, Stanley, "Buenas noches compañeros. Historias de vida en alcohólicos anónimos", Revista de Antropología Social. 13, pp. 113-136.

(2010) BURBANO, Gelpud, "Caracterización de las creencias religiosas de las estudiantes de la institución educativa Boyacá". Trabajo de grado para aspirar al título de Maestría en Educación. Universidad Tecnológica de Pereira.

(2010) DELGADO, Manuela, La razón hechizada. Teorías Antropológicas de la religión, Ed. Ariel, Barcelona.

(2010) DAMASIO, Antonio, Y el cerebro creo al hombre, Ed. Destino, España.

(1998) DE LA PINEDA, Avelino, El problema de la religión, Ed. SINTESIS, Madrid.

(1998) Díaz, Rodrigo, Archipiélago de rituales. Teorías antropológicas del ritual, Ed. AnthroposUAM, Barcelona.

(1994) DÍAZ, Rodrigo, "Purificar las palabras de la tribu, antropología simbólica y razón austera",Alteridades, 4, (8), pp. 31-40.

(2000) DURKHEIM, Emilio, Las formas elementales de la vida religiosa, Ed. Colofón, México.

(1999) ELIADE, Mircea,Historia de las creencias y las ideas religiosas. Ed. Paidós, Barcelona.

(1981) FRAZER, James, La rama dorada, Ed. FCE, México.

(1997) GEERTZ, Clifford, La interpretación de las culturas, Ed. Gediza, Barcelona.

(2004) GONZÁLEZ, Teresa, "Las creencias religiosas y su relación con el proceso saludenfermedad",Revista Electrónica de Psicología Iztacala, 7 (2), pp. 19-29.

(1997) HARRIS, Marvin, Nuestra especie, Ed. Alianza, Madrid.

(2005) HERVIEU-LÉGER, Daniele, La religión, hilo de memoria. Ed. Herder, Barcelona.

(1999) JAMES, William, Las variedades de la experiencia religiosa, Ed. Península, Barcelona.

(2010) LINDEN, David, El cerebro accidental, Ed. Paidós, Barcelona.

(1973) LUCKMANN, Thomas, La religión invisible. El problema de la religión en la sociedad moderna, Ed. Sígume, Salamanca.

(2006) MEJÍA, Santiago, "Wittgenstein y la creencia religiosa”, Ideas y Valores. 55 (132), pp. 3-29.

(1985) MALINOWSKI, Bronislaw, Magia, ciencia y religión,Ed. Planeta-Agostini, Barcelona.

(1973) MALINOWSKI, Bronislaw, Los Argonautas del Pacífico Occidental, Ed. Penúnsula, Barcelona.

(1988) MARDONES, José, Postmodernidad y cristianismo. El desafío del fragmento, Ed. Sal Terrae, Santander.

(1996) MARDONES, José, ¿A dónde va la religión? Cristianismo y religiosidad en nuestro tiempo, Ed. Sal Terrae, Santander.

(2009) MÓDENA, María, "Diferencias, desigualdades y conflicto en un grupo de Alcohólicos Anónimos",Desacatos,29, pp. 31-46. 
(2010) MONTES DE OCA, Verónica, "Pensar la Vejez y el envejecimiento en el México contemporáneo",Renglones, 62, pp. 158-181.

(1979) RUSSELL, Bertrand, Por qué no soy cristiano, Ed. EDHASA, Barcelona.

(2005) RYLE, Gilbert, El concepto de lo mental, Ed. Paidós, Buenos Aires.

(1968) Ortega y Gasset, José, Ideas y creencias, Ed. Espasa-Calpe, Madrid.

(2007) OTTO, Rudolf, Lo santo. Lo racional y lo irracional en la idea de Dios, Ed. Alianza, Madrid.

(1994) PEREDA, Carlos, Razón e incertidumbre,Ed. S. XIX, México.

(1978) PEREIRA DE QUEIROZ, María, Historia y etnología de los movimientos mesiánicos,Ed. S.XXI, España.

(2010) POLANCO, Graciela y María del Rocío Orellana, "Creencias religiosas en el fenómeno migratorio mexicano". En La migración en México y su impacto en la vida social de las personas. Jesús Heraclio del Rio (coord.) México: Universidad Anáhuac México / AMIESIC, pp. 335-343

(2000) PUJADAS, Joan, "El Método Biográfico y los géneros de la memoria",Revista de Antropología Social, 9, pp. 27-158.

(1998) QUESADA, Daniel, Saber, opinión y ciencia, Ed. Ariel, Barcelona.

(2009) RAMíREZ, Juan y Renée de la Torre, "El respeto a las creencias religiosas y la libertad de expresión artística. El caso de "La Patrona". Espiral, Estudios sobre el Estado y sociedad. XV (44), pp. 199-251.

(2006) ROBLES, Leticia, Silva et.al, Miradas sobre la vejez. Un enfoque antropológico,Ed.El Colegio de la Frontera Norte / Plaza y Valdés, México

(1978) SÁDABA, Javier, Qué es un sistema de creencias,Ed. Mañana, Madrid.

(1972) SCHUTZ, Alfred, Fenomenología del mundo social,Ed. Paidós, Buenos Aires.

(2003) SCHUTZ, Alfred y Thomas Luckmann, Las estructuras del mundo de la vida. Vol. 1, Ed. Amorrortu, Buenos Aires.

(2009) SOTO-SONERA, José, "Influencia de las creencias religiosas en los docentes de ciencia sobre la teoría de la evolución biológica y su didáctica",Revista Mexicana de Investigación Educativa,14 (41), pp. 515-538.

(1999) THOMPSON, John, Ideología y cultura moderna,Ed. UAM-X, México.

(1977) TYLOR, Edward, Cultura primitiva, Tomo I,Ed. Ayuso, Madrid.

(1992) VILLORO, Luis, Creer, saber, conocer,Ed. S.XXI, México.

(2001) VÁZQUEZ, Felipe, Contando nuestros días: Un estudio antropológico de la vejez,Ciesas, México.

(1996) WEBER, Max, Economía y sociedad,Ed. FCE, México.

(2002) WITTGENSTEIN, Ludwig, Lecciones y conversaciones sobre estética, psicología y creencia religiosa,Ed. Paidós, Buenos Aires. 